\title{
Umfangreichere Tests für junge NSCLC-Patienten
}

\author{
Genmutationen sind bei NSCLC-Patienten unter 50 Jahren signifikant häufiger \\ als bei älteren. Gute Voraussetzungen für gezielte Therapien. Doch die Pro- \\ gnose der jüngsten Patienten fiel in einer US-Studie unerwartet schlecht aus.
}

M/eniger als $5 \%$ der Patienten mit nichtkleinzelligem Lungenkarzinom (NSCLC) sind zum Diagnosezeitpunkt jünger als 50 Jahre. Doch sie weisen einige genetische Besonderheiten auf, die therapeutisch genutzt werden könnten und denen bislang offenbar zu wenig Beachtung geschenkt wird. Adrian G. Sacher und Kollegen analysierten retrospektiv eine Kohorte mit 2.237 Patienten, die zwischen 2002 und 2014 genotypisiert worden waren. Mithilfe eines multivariaten Cox-Modells wurde nach $\mathrm{Zu}$ sammenhängen zwischen nachweisbaren genomischen Veränderungen im jüngeren Alter und der Prognose gesucht.

Insgesamt wurden bei $32 \%$ aller Patienten Genveränderungen wie EGFRKinase-Mutationen, ALK- oder ROS1Rearrangements, ERBB2-Kinase- oder BRAF-V600E-Mutationen nachgewiesen. Dabei fand sich ein Zusammenhang zwischen Genotyp und Alter: Bei Diagnose jüngere Patienten wiesen im Vergleich zu älteren Patienten gehäuft

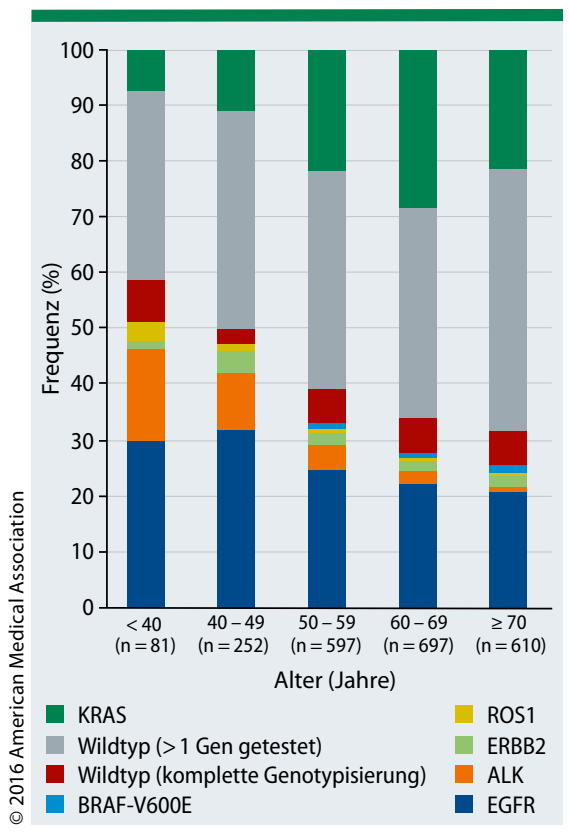

Abb. 1: Frequenz möglicher zielgerichtet ansteuerbarer genomischer Veränderungen.
EGFR-Kinase-Mutationen $(\mathrm{p}=0,02)$ und ALK-Rearrangements $(\mathrm{p}<0,01)$ auf (Abb. 1). Ein ähnlicher, wenn auch nicht signifikanter Trend zeigte sich bei ERBB2 $(\mathrm{p}=, 15)$ und ROS1 $(\mathrm{p}=0,1)$. Bei jüngeren Patienten $(<50$ Jahre) wurde mit einer um $59 \%$ höheren Wahrscheinlichkeit als bei älteren ( $\geq 50$ Jahre) einer der untersuchten Genotypen festgestellt. Möglicherweise stellen jüngere Patienten somit eine genetisch besondere Subgruppe dar - mit Konsequenzen für die Behandlung. Denn durch Therapien, die gezielt genetische Veränderungen angriffen, verbesserte sich das Überleben um $34 \%$. Wurden Patienten mit nachweisbaren Genveränderungen dagegen nicht gezielt behandelt, hatten sie keinen Vorteil. Anders als erwartet, ergab die Analyse für die jüngsten wie auch für die ältesten Patienten die schlechtesten Prognosen. Unter 40-Jährige überlebten median 18,2 Monate, über 70-Jährige 13,6 Monate - verglichen mit 22,9 Monaten für 40-49-Jährige, 21,3 Monaten für 50-59-Jährige und 18,3 Monaten für 60-69-Jährige. Selbst unter 40-Jährige mit nachgewiesener Genmutation erreichten nur 21,4 Monate. Am längsten (35,4 Monate) überlebten 50-59-Jährige mit Mutationen.

Fazit: Trotz nachgewiesener Mutationen und gezielter Therapien war das Überleben der jüngsten NSCLC-Patienten gegenüber anderen Altersgruppen unerwartet schlecht. Womöglich, so die Forscher, sei hierfür ein aggressiverer Krankheitsverlauf mitverantwortlich. Nötig seien spezielle Therapiekonzepte sowie Genotypisierungen bei jüngeren Patienten auch mittels „next generation sequencing“. Damit könnten auch seltene und bislang unbekannte Mutationen erkannt und mehr junge Patienten gezielt behandelt werden. Christine Starostzik

Sacher AG et al. Association Between Younger Age and Targetable Genomic Alterations and Prognosis in Non-Small-Cell Lung Cancer. JAMA Oncol. 2016;2(3):313-20. 